\title{
Metacognição e funções executivas: em busca de diálogos
}

\author{
Metacognition and executive functions: in search of dialogues \\ Metacognición y funciones ejecutivas: en busca de diálogos
}

\author{
Flávia Acco (flavia.acco@outlook.com) \\ Universidade de Passo Fundo.
}

Cleci T. Werner da Rosa (cwerner@upf.br)

Universidade de Passo Fundo.

\begin{abstract}
Resumo: O presente texto se ocupa de discorrer sobre o entendimento de metacognição e de funções executivas como forma de verificar suas aproximações e dissonâncias, especialmente no modo como vêm sendo avaliados enquanto estrutura de pensamento e ação dos sujeitos no contexto educativo. Para tanto, toma-se como linha norteadora a descrição desses dois temas segundo autores tidos como referência nas respectivas áreas envolvidas na pesquisa e a partir deles infere-se discussões às pesquisas desenvolvidas, especialmente a forma como a metacognição e as funções executivas têm sido avaliadas nos sujeitos, ou seja, os questionários ou testes tradicionalmente utilizados. No caso das funções executivas esses testes são recorrentes na literatura, todavia, em termos da metacognição eles se revelam em número escasso como evidenciado pela busca realizada em duas bases de dados na qual foi encontrado apenas dois testes.
\end{abstract}

Palavras-chave: testes neuropsicológicos; questionamentos metacognitivos; processo de aprendizagem.

Abstract: The current essay expatiate on the understandment of metacognition and executive functions as a way to verify its approach and dissonance, especially in the way they have been evaluated as thought structure and actions of the subjects in the educational context. For this purpose, the description taken as guidance of these two themes according to some authors who were reference in the respective areas involved and they result discussions about the developed researches, especially the way how metacognition and its executives functions have been evaluated in the subjects, in other words, the questionnaires or tests traditionally used. In the case of the executive functions these tests are recurring in literature, however, in terms of metacognition they reveal themselves in low numbers as proved by the research held in both data bases in which only two tests were found.

Keywords: neuropsychological tests; metacognition quoting; learning process.

Resumen: Este texto se ocupa de discutir la comprensión de la metacognición y las funciones ejecutivas como una forma de verificar sus aproximaciones y disonancias, especialmente en la forma en que han sido evaluadas como estructura de pensamiento y acción de los sujetos en el contexto educativo. Para ello, se toma como guía la descripción de estos dos temas, según los autores tomados como referencia en las respectivas áreas involucradas en la investigación, y de ellos se infieren discusiones a la

Recebido em: 07/12/2020

Aceite em: 25/08/2021 
investigación realizada, especialmente la forma en que la metacognición y En las asignaturas se han evaluado las funciones ejecutivas, es decir, los cuestionarios o pruebas tradicionalmente utilizados. En el caso de las funciones ejecutivas, estas pruebas son recurrentes en la literatura, sin embargo, en términos de metacognición se revelan en un número escaso, como lo demuestra la búsqueda realizada en dos bases de datos en las que solo se encontraron dos pruebas.

\section{Palabras-clave: pruebas neuropsicológicas; preguntas metacognitivas; proceso de aprendizaje.}

\section{INTRODUÇÃO}

Compreender o modo como determinado sujeito maneja suas ações e percepções em torno de si mesmo e de suas relações com sua comunidade, é um dos postulados do estudo acerca da metacognição. Valenzuela (2019, p. 11) exprime que tal constructo é um conceito que demarca o indivíduo como protagonista de seu processo de pensamento. Rosa (2014, p. 25) corrobora mencionando que "o sujeito deverá ser capaz, cada vez mais, de entender suas capacidades e suas limitações, pondo-as em prática, a fim de realizar suas tarefas com êxito". Nessa perspectiva, o sujeito se colocar de modo consciente a respeito dos processos mentais que vivencia o que é intrínseco aos manejos que seguirá diante de suas respectivas narrativas ou na execução de suas ações.

Com a finalidade de criar um canal entre o sujeito e a compreensão de seu alicerce metacognitivo, as escalas neuropsicológicas surgem propondo meios de mensurar a metacognição e, nesse sentido, proporcionar que eventuais modificações no aporte cognitivo sejam realizadas, obtendo dessa forma, maior qualidade de vida aos sujeitos. Entretanto, Lima Filho e Bruni (2015, p. 1277) ressaltam que no espectro das ciências humanas, há demarcadores que não são passíveis de uma aferição concreta, ou seja, são mais difíceis de serem medidos, e a metacognição pode ser considerado um deles. Dessa maneira, o percurso para que se construam métodos válidos para a aferição das manifestações metacognitivas se apresenta como um desafio aos pesquisadores e disso vem sendo estabelecidas relações com outros conceitos ou sendo medido indiretamente, de modo a auxiliar esse diagnóstico sobre a consciência metacognitiva de cada sujeito.

É notório, todavia, o esforço dos pesquisadores em produzir mecanismos cuja finalidade é capturar determinados atributos metacognitivos dos sujeitos por meio de suas ações. Flavell (1976), precursor nos estudos envolvendo metacognição, cita 
exemplos de expressão que podem ser utilizadas por um sujeito para verificar se está ativando essa forma de pensamento. Nas palavras do autor:

Por exemplo, eu estou praticando a metacognição (metamemória, meta-
aprendizagem, meta-atenção, metalinguagem, ou outros), se me dou conta de
que tenho mais dificuldade para aprender A do que B; se compreendo que
devo verificar C antes de aceitá-lo como verdade (fato); quando me ocorre
que eu teria de examinar melhor todas e cada uma das alternativas em algum
tipo de teste de múltipla escolha, antes de decidir qual é a melhor; se eu
estiver consciente de que não estou seguro que o experimentador realmente
quer que eu faça; se eu perceber que seria melhor tomar nota de D porque
posso esquecê-lo; se eu pensar em perguntar a alguém sobre E, para ver se
está correto. Esses exemplos podem se multiplicar indefinidamente
(FLAVELL, 1976, p. 232, tradução nossa).

A partir desses exemplos o autor formula um conceito mais abrangente e geral para a metacognição, destacando que ela "se refere, entre outras coisas, à avaliação ativa e consequente regulação e orquestração desses processos em função dos objetivos e dados cognitivos sobre o que se quer e, normalmente, a serviço de alguma meta ou objetivo concreto" (FLAVELL, 1976, p. 232).

Esses exemplos trazidos por Flavell que demonstram como a metacognição é passível de análise. Contudo, seus vislumbres apenas são assimilados diante da contextualização das tomadas de ação dos sujeitos. Em outras palavras, por mais que a metacognição envolva a tomada de consciência do sujeito sobre seus próprios conhecimentos e a posterior regulação das ações - autorregulação -, é no estabelecimento de metas ou diante de uma ação que o processo se estabelecer.

As Funções Executivas (FE), por sua vez, podem ser entendidas como um conjunto de habilidades e capacidades que nos permite executar ações necessárias para atingir um objetivo. Nelas estão contempladas ações que envolvem planejar, executar, verificar, controlar e estabelecer metas e procedimentos para resolução de problemas, entre outras ações (COSENZA; GUERRA, 2011). Segundo os mesmos autores, o desenvolvimento das FE deve ser impulsionado por meio de estratégias.

Seguem os autores relatando que:

Elas devem estar voltadas para que os estudantes aprendam a planejar suas atividades, decompondo-se em subtarefas que possam ser desenvolvidas, sendo capazes de estabelecer metas dentro de uma perspectiva temporal. Pretende-se que eles saibam não só buscar a informação utilizando os recursos existentes, mas que saibam também, identificar as questões relevantes (COSENZA; GUERRA, 2011, p. 94). 
Tais entendimentos subsidiaram a elaboração do presente texto que se ocupa de apresentar a compreensão de metacognição e de FE, evidenciando as aproximações e o modo como esses temas vem sendo avaliados enquanto estrutura de pensamento e ação dos sujeitos, particularmente no contexto educativo.

\section{METACOGNIÇÃO E FUNÇÕES EXECUTIVAS: APROXIMAÇÕES}

O entendimento de metacognição tem sido associado a expressão "pensamento do pensamento" ou "cognição da cognição". Autores como Weinert (1987) manifestam que ela representa um empreendimento cognitivo de segunda ordem, uma vez que reúne um conjunto de elementos que estão vinculados a uma estrutura de pensamento de natureza interna do sujeito, cuja origem não surge de uma realidade externa imediata, mas das representações mentais internas próprias de cada pessoa sobre aquela realidade. Martí (1995) mostra que a metacognição, além de ser um dos aspectos constituintes do desenvolvimento cognitivo, é encarregada da constituição da cognição em si, isto é, metacognição e cognição são indissociáveis, pois a cognição envolve metacognição.

O apresentado remete ao entendimento de que a compreensão de metacognição encontra-se associado ao de cognição, dissociando-se dessa pelo fato de ser um processamento interno decorrente dos primeiros significados atribuídos pelos sujeitos que, por sua vez, são entendidos como cognitivos. Essa cognição da cognição foi detalhada por Flavell ao longo de suas pesquisas e acabou tomando sentidos variados, especialmente por sofrer adaptações as diferentes áreas que se serviram desse conceito. Atualmente não há um consenso sobre o conceito de metacognição, todavia, há sobre suas origens - atribuídas aos estudos de Flavell na década de 1970, e sobre a existência de um denominador comum que está relacionado à tomada de consciência do sujeito sobre seus conhecimentos, sobre seu modo de pensar, promovendo a regulação de suas ações.

Rosa (2011, p. 57) na busca por trazer o conceito de Flavell para o contexto educacional anuncia que a "Metacognição é o conhecimento que o sujeito tem sobre seu conhecimento e a capacidade de regulação dada aos processos executivos, somada ao controle e à orquestração desses mecanismos". Com isso, a autora aponta a existência de dois componentes: um relacionado ao conhecimento que o sujeito tem sobre seu próprio conhecimento (conhecimento metacognitivo) e outro vinculado à ação executiva

Recebido em: $07 / 12 / 2020$

Aceite em: 25/08/2021 
e autorreguladora (habilidades metacognitivas). Soma-se a esses componentes as experiências metacognitivas que estão diretamente vinculadas ao conhecimento metacognitivo e entendidas por Flavell (1979, p. 906-907, tradução nossa) como "quaisquer experiências conscientes cognitivas ou afetivas, que acompanham e pertencem a toda empreitada intelectual".

Nessa linha e ao analisarmos o segundo componente metacognitivo - controle executivo e autorregulador -, percebemos que está vinculado ao que Brown (1978; 1987), responsável por estudos que permitiram detalhar esse componente, menciona como a operacionalização a partir de uma dada meta, tendo como pano de fundo uma ação consciente do sujeito sobre próprio conhecimento. A autora concebe que o sujeito, ao compreender esse conhecimento, poderá utilizá-lo adequadamente na realização das atividades e, portanto, terá condições de colocá-lo em operação para lograr êxito em sua atividade. Essa operacionalização pode ser analisada a partir de diferentes elementos metacognitivos, dentre os quais a autora pontua três: planificação, monitoração e avaliação.

De acordo com Rosa (2011, p. 54-56, destaque da autora) esses elementos são assim entendidos:

\begin{abstract}
A planificação é a responsável pela previsão de etapas e escolha de estratégias em relação ao objetivo pretendido, o que supõe fixar metas sobre como proceder para realizar a ação. [...] A monitoração consiste em controlar a ação e verificar se está adequada para atingir o objetivo proposto, avaliando o desvio em relação a este, percebendo erros e corrigindo-os, se necessário. [...] A avaliação identifica-se com os resultados atingidos em face do fim visado, podendo, eventualmente, ser definida pelos critérios específicos de avaliação.
\end{abstract}

Esses elementos metacognitivos e que representam uma ação de estruturação do pensamento desencadeada pela tomada de consciência do sujeito sobre seus próprios conhecimentos e que, no entender de Flavell (1979), também estão ligados a sentimentos (experiências metacognitivas), representam o ponto onde as discussões em metacognição se aproximam do que entendemos como Funções Executivas. Corso et al. (2013, p. 26) mostram essa aproximação mencionando que ambas "descrevem as atividades mentais de planejamento, monitoramento, e controle das próprias ações". Nessa perspectiva, um sujeito ao realizar, por exemplo, a leitura de um texto irá utilizar em seu arcabouço cognitivo ferramentas das duas proposições teóricas - devido a essas estarem integradas nos processos da mente. A leitura como expresso por Vale (2020) é

Recebido em: $07 / 12 / 2020$

Aceite em: 25/08/2021 
um hábito que repercute positivamente no desenvolvimento do sujeito, trazendo benefício intelectual e cognitivo.

Sobre as FE, segundo Diamond (2014, p. 7), podemos entendê-las como família de processos em constante interação, os quais são extremamente necessários quando determinado sujeito necessita se concentrar, prestar atenção, agir de "modo automático" ou pressupor que determinada atividade e a ser realizada não obterá êxito - desse modo, são intrínsecos à inserção do indivíduo no tecido social. Nesse sentido, o uso das FE viabiliza que as atividades/vivências de um sujeito sejam realizadas de um modo mais brando, tal qual um catalisador. A autora também apresenta o agrupamento das FE em três núcleos: controle inibitório, memória de trabalho e flexibilidade cognitiva.

O controle inibitório é definido como uma capacidade do sujeito para manejar sua atenção, comportamento, pensamentos e emoções (DIAMOND, 2014. p. 7), na mesma medida em que contém os impulsos de apresentá-los ao ambiente externo, isto é, filtrar os conteúdos que serão compartilhados com outrem. Dessa forma, há certa análise do que deve e não deve ser exteriorizado. Diamond (2014, p. 7, tradução nossa) também desfere que:

Ter a presença de espírito de esperar antes de falar ou agir, e então dar uma resposta propícia ao invés de uma impulsiva - pode nos salvar de fazermonos de tolos e nos auxilia a demonstrar o melhor da nossa capacidade. Autocontrole é o aspecto do controle inibitório que envolve a resistência à tentações e ao não agir impulsivamente.

Nesse sentido, o controle inibitório se demonstra crucial para que os sujeitos sejam passíveis de regular suas interações com o mundo e com eles mesmos. A capacidade de exercer modificações em padrões de comportamento também é oriunda da função executiva citada, ou seja, apenas é possível que um sujeito se desenvolva e modifique padrões, assim como instaure novos espectros nas relações humanas, por meio do manejo do controle inibitório.

O segundo núcleo das FE, é o da memória de trabalho, é definida por Baddeley (2000) como a capacidade do sistema cognitivo de um sujeito para permitir armazenamento temporário e manejo de informações necessárias para a realização de determinadas tarefas, como, por exemplo, a compreensão de um texto. Uehara e Landeira-Fernandez (2010), expõem a diferenciação entre memória de trabalho e memória de curto prazo, as quais se distinguem pela priorização de determinadas

Recebido em: 07/12/2020

Aceite em: 25/08/2021 
informações ao serem retidas na memória, isto é, o fator do tempo para a memória de trabalho não é o principal determinante. Já a utilidade imediata das novas informações adquiridas se demonstra como crucial para a memória de trabalho. Um exemplo de tal premissa é um sujeito reter somente informações pertinentes ao realizar a elaboração de um escrito acadêmico, dessa forma potencializa a construção de seu conhecimento.

Diamond (2014) afirma que a memória de trabalho é uma das principais condutoras para o desenvolvimento do raciocínio. Sem ela, um sujeito não seria hábil para destrinchar e relacionar informações partindo de uma ideia geral, assim como considerar suposições alternativas, a essa ideia geral, de forma crítica. A autora também apresenta a influência dessa FE para a criatividade dos sujeitos, devido a essa envolver o desmanche e a criação de elementos em novos arranjos.

O terceiro núcleo é representado pela flexibilidade cognitiva, em que tal função se baseia/permeia ou relaciona com os outros dois núcleos apresentados anteriormente (DIAMOND, 2014). Esse núcleo possui como cerne, a habilidade de modificar perspectivas, espaciais ou interpessoais, como por exemplo, entender diferentes contextos sociais que não foram vivenciados pelo sujeito que se propõe a elucidá-los ou captar como certa paisagem (uma floresta, p.ex.) seria se o ponto de observação estivesse no ângulo oposto ao espectador. Por conseguinte, é necessário frisar que para a modificação de uma perspectiva seja efetuada, às preconcepções necessitam ser temporariamente desativadas, instaurando assim, uma nova - por meio da memória de trabalho. Essa também se relaciona com a flexibilidade cognitiva (DIAMOND, 2014, p. 8), nos processos de modificações de padrões de pensamento - modificando o modo como o sujeito pensa sobre algo. Um exemplo é a criação de novas maneiras para se utilizar um objeto, como um clipe de papel. A maneira regular de se utilizar tal instrumento é a de unir folhas de papel, entretanto, ao atenuar tal concepção de uso, uma pessoa pode criar novos modos de utilizá-lo - como um alfinete ou até mesmo como uma presilha de cabelo.

Conjuntamente, a flexibilidade cognitiva permeia o estabelecimento de prioridades ou modificação de demandas, bem como saber manejar situações que estavam fora do esperado (DIAMOND, 2014). A flexibilidade cognitiva está ligada com a tolerância a frustração de um sujeito, visto que ao saber realizar o manejo de situações imprevistas, ele também está demonstrando que consegue suportar o inesperado e a sua

Recebido em: $07 / 12 / 2020$

Aceite em: 25/08/2021 
consequente frustração pelo não acontecimento do que fora planejado. Nessa perspectiva, determina-se - então - o papel protagonista das FE para o desenvolvimento cognitivo, social, psicológico e físico de um sujeito (DIAMOND, 2014).

Um sujeito, que apresenta bom domínio dos núcleos apresentados anteriormente, possui um bom desempenho das FE (SANTANA; MELO; MINERVINO, 2019). Quando tal premissa se apresenta de modo contrário, isto é, quando um sujeito possui dificuldades em manejar suas FE, uma das causalidades para tal conflito é a disfunção executiva. Elas são refletidas em dificuldades que impactam as vivências de um indivíduo, como comprometimento da atenção sustentada, dificuldade em iniciar tarefas, problemas de planejamento e falta no controle de impulsos (SABOYA et al., 2007. p. 32).

No tocante à relação da metacognição com as FE temos o estudo de Corso et al. (2013) que apontam elementares a respeito da temática, os quais serão apresentados no decorrer destes parágrafos. Nesse viés, os autores denotam que o processo do aprender está intrinsecamente relacionado com o manejo das capacidades de planejamento, assim como a regulação da própria atividade (p. 21), tendo como finalidade alavancar determinados objetivos. Partindo dos temas de estudos desse texto é possível inferir que tanto a metacognição quanto às FE desempenham importante papel nesse processo e são responsáveis por mecanismos que permitem controlar e regular a ação cognitiva dos sujeitos.

Tal identificação leva a necessidade de relacionar os constructos, principalmente em um cenário educativo, visto que ao elucidar as cadeias psicológicas e neuropsicológicas da aprendizagem humana, os manejos referentes ao aprendizado se tornam passíveis de possuir seus respectivos potenciais alavancados (CORSO et al., 2013, p. 23). Seguem os autores mencionando que ambos constructos "descrevem as atividades mentais de planejamento, monitoramento e controle das próprias ações" (p. 26), na mesma medida que circundam uma vasta área de intersecção entre os mesmos. Tal premissa denota, também, certa lacuna quanto à definição dos conceitos. Sabemos que dentro das duas áreas há diversos impasses referentes a uma definição global para as conceituações, como já evidenciado neste texto. Os autores concernem a esse entrave, uma falta de precisão de ambos os campos, assim como sugerem que a evolução da definição de metacognição e FE ocorrem, atualmente, na perspectiva da 
modificação dos domínios ou elementos que os compõem, sendo esses definidos como segmentações das áreas de pesquisa ou incorporações de constructos já existentes.

De forma geral, sabemos da existência de estudos propondo articular as duas áreas citadas. Perrotin, Tournelle e Isgrini (2008), por exemplo, sugerem a efetividade da metamemória como um produto do funcionamento executivo, o que se revela presente tanto no domínio da metacognição como das FE. Todavia, como já mencionado, qualquer tentativa de aproximação precisa ser realizada com cautela, pois ainda há necessidade de ampliar as pesquisas neste campo de aproximação, visto que por possuírem pilares semelhantes, não se pode preterir às possíveis descobertas no manto de tal direcionamento, isto é, o uso da relação conceitual apresentada pode exercer modificações na forma como se estuda o processo do aprendizado. Dessa forma, novos métodos podem ser desenvolvidos, os quais são passíveis de transformações efetivas em uma das bases que orientam o progresso dos sujeitos na percepção deles mesmos.

A metacognição pode ser vista como um catalisador frente à aquisição do conhecimento, devido sua efetividade em aprimorar as habilidades de aprendizagem (ANDRETTA et al., 2010). O modo como os indivíduos se colocam a refletir sobre seus respectivos funcionamentos e os manejos que escolhem para realizar as tarefas de seus cotidianos se mostra intrínseco ao seu progresso. Rosa $(2014$, p. 25$)$ desfere que "é o conhecimento que as pessoas têm sobre elas mesmas que afeta o seu rendimento na realização de tarefas". Nesse tangenciamento, a busca pelo entendimento das bases escolhida pelos sujeitos nas consolidações de seus processos cognitivos - por meio da metacognição - se estabelece como uma influente área de pesquisa.

Em particular, se olharmos para a metacognição, construto mais presente no contexto escolar, verificamos que maiores investimentos são necessários acerca da pesquisa, o que pode estar dificultando essa aproximação mais efetiva entre um tema emergente da psicologia e um utilizado na Educação. No Brasil, por exemplo, a produção científica nacional a respeito da metacognição se apresenta em maior grau no tecido educacional, enquanto sobre FE, se localiza na Psicologia, embora ambos se revelam concernentes a aprendizagem. Rosa e Schmitz (2020) mapearam 22 teses e dissertações relativas ao período de 2013 a 2017 sobre a presença da metacognição nos estudos no campo da Educação. No estudo as autoras apontaram para: a existência de um reduzido número de trabalhos envolvendo a temática; a ênfase em processos

Recebido em: $07 / 12 / 2020$

Aceite em: 25/08/2021 
relacionados a aprendizagem em Matemática; a presença de estudos envolvendo expertise e sua vinculação com o pensamento metacognitivo; a predominância da abordagem qualitativa nas pesquisas; e, os escassos estudos aproximando a metacognição do domínio afetivo. Adotando os mesmos critérios de análise, porém analisando as teses e dissertações produzidas de 2013 a 2017, encontramos um universo de FE e Educação encontramos oito trabalhos, cujos resultados apontam para seu emprego em situações de dificuldade de aprendizagem ou para situações com distúrbios neuropsicológicos.

Nesses estudos temos a tese intitulada "Intervenções em funções executivas, estratégias metacognitivas e consciência fonêmica em estudantes com dislexia do desenvolvimento", desenvolvida por Giovanna Beatriz Kalva Medina em 2018 na Universidade Federal do Paraná. O estudo envolveu 14 alunos que apresentavam dislexia do desenvolvimento, 14 estudantes com a mesma idade cronológica dos disléxicos (GCI) e nove estudantes mais jovens (GCL), divididos em grupo experimental e de controle. A intervenção ocorreu em 29 sessões realizadas uma vez por semana, durante sete meses. Nessas sessões foram realizadas atividades para o desenvolvimento das FE e da consciência fonêmica, além da estimulação do uso de estratégias metacognitivas. Como resultado o estudo apontou que após a intervenção, não foi encontrada diferença significativa no desempenho dos grupos na maioria das funções executivas, com exceção do controle inibitório/atenção seletiva onde o grupo dos disléxicos teve desempenho superior ao dos estudantes mais jovens. No que se refere ao uso de estratégias metacognitivas, não houve diferença estatisticamente significativa entre o desempenho dos grupos, no entanto, segundo a autora, foi possível verificar diferença de desempenho significativa entre o grupo dos disléxicos e do estudante mais jovem, em favor dos disléxicos do grupo experimental. Estes resultados permitem concluir que a intervenção implementada junto aos disléxicos não produziu um aumento de desempenho significativo em todas as funções executivas trabalhadas, mas que a intervenção foi eficiente em termos de promover a leitura de palavras isoladas e compreensão de sentenças e pequenos textos.

\section{RESULTADO E DISCUSSÕIES DA PESQUISA}


Para atender o objetivo do estudo, procedemos uma pesquisa qualitativa, bibliográfica e focada na identificação dos instrumentos utilizados para avaliar o pensamento metacognitivo e as FE. Essa busca foi realizada junto as bases de dados SciELO e PePSIC, como será relatado mais adiante.

Em relação a avaliação do pensamento metacognitivo, Georghiades (2004) chama a atenção para a dificuldade de avaliar o pensamento dos sujeitos, mencionando que a metacognição é um processo interno e de difícil exteriorização pelos sujeitos. Isso naturalmente tem contribuído para a dificuldade em identificar e avaliar a presença dessa forma de pensamento nos estudos realizados nessa área Nessa perspectiva, há necessidade de um número maior de estudos para que o discernimento a respeito dos mecanismos da população brasileira em lidar com suas respectivas jornadas vivenciais seja elucidado. Tal avanço é crucial, visto que após a identificação dos mecanismos metacognitivos de um sujeito é possível que esses sejam modificados e aprimorados.

Embora seja constatada essa dificuldade, as pesquisas vêm se servindo de diferentes instrumentos para mapear a presença do pensamento metacognitivo no sujeito, a exemplo do que ocorre com as FE. Dentre os instrumentos estão os questionários ou testes que buscam uma mensuração do pensamento metacognitivo ou, alternativamente, das FE. Nesse caso é necessário discernir entre aqueles que avaliam a presença desses temas de forma integralizada ou que procedem a uma dissociação em elementos, onde cada um é analisado separadamente e depois integrado na forma de rede. Esse processo de avaliação integrada, sem a identificação por elemento ou itens, tem sido utilizado no Brasil, principalmente em termos da avaliação do pensamento metacognitivo.

Em uma busca junto as bases de dados SciELO e PePSIC e recorrendo ao uso dos descritores "metacognição", "avaliação psicológica" e "mensuração" e, posteriormente, com o refinamento utilizando "produção científica", identificamos dois testes para avaliar o pensamento metacognitivo: O EMETA e o MAI. O primeiro foi elaborado por Pascualon-Araujo e Schellini (2013) e representa uma escala neuropsicológica de rastreio de habilidades metacognitivas em crianças, possuindo como foco a autorregulação metacognitiva. A estruturação desse teste se dá em uma escala do tipo Likert com seis apontamentos, na qual o infante escolhe o que mais lhe condiz (PASCUALON-ARAÚJO; SCHELINI, 2015).

Recebido em: $07 / 12 / 2020$

Aceite em: 25/08/2021 
Após a fase de testes, a sua versão final se configurou em quesitos articulados à:

utilização de estratégias para avaliar o próprio desempenho durante e após a execução de uma tarefa, mudança de estratégia ineficiente adotada em uma atividade, conhecimentos relativos às tarefas a serem realizadas, conhecimento acerca de características pessoais e conhecimento sobre variáveis relacionadas a desempenhos mais eficientes em tarefas específicas (PASCUALON-ARAUJO; SCHELINI, 2015, p. 168).

As autoras também complementam que "os diferentes aspectos da metacognição são avaliados por itens que apresentam um conceito em comum, fato esse que determina a não existência de dois ou mais fatores que abrangeriam aspectos diferentes do conceito" (p. 169). Nesse sentido, houve a nomeação de um único fator de mensuração na escala, intitulado de "metacognição". A EMETA ainda passa por estudos que corroborem sua validade para que sua finalidade seja operada de acordo com as normas.

Em relação a avaliação das FE de um sujeito, recorremos a uma análise neuropsicológica. Faria, Alves e Charchat-Fichman (2015) exprimem que as disfunções executivas podem ser aferidas de modo objetivo através da testagem neuropsicológica, a qual apresenta uma densa gama de testes destinados às FE. Não obstante, também afirmam que devido, justamente, a essa ampla variedade de instrumentos, é que se torna necessário um crivo sensibilizado no momento de determinar quais testes são recomendados para determinados sujeitos. A pesquisa de Santana, Melo e Minervino (2019), mostra que é passível de percepção a ampla utilização de dois ou mais testes combinados para garantir a consistência da avaliação das FE. Os autores após uma pesquisa nas bases de dados Scientific Electronic Library Online (SciELO), Index Psi Periódicos (INDEXPSI), Literatura Latino-Americana e do Caribe em Ciências da Saúde (LILACS), Periódicos Eletrônicos de Psicologia (PePSIC) e nos periódicos disponíveis no site da Coordenação de Aperfeiçoamento de Pessoal de Nível Superior (CAPES), apontaram 35 artigos vinculados ao tema Avaliação das FE. Dentre os testes existentes, de acordo com os autores, os mais utilizados são os seguintes: Teste Wisconsin de Classificação de Cartas (WCST), Escalas Wechsler (WISC/WAIS/WIAT e WPPSI), Teste das Trilhas (Trail Making Test), Teste Stroop (numérico, sonoro e pictórico) e Hayling Test.

O segundo instrumento localizado na busca e em se tratando da avaliação do pensamento metacognitivo foi o Metacognitive Awareness Inventory - MAI, desenvolvido por Gregory Schraw e Rayne Sperling Dennison (1994). A ferramenta é

Recebido em: 07/12/2020

Aceite em: 25/08/2021 
amplamente utilizada no cenário educacional, inclusive brasileiro, e destina-se a identificar a consciência que os sujeitos possuem em relação ao seu conhecimento e suas habilidades metacognitivas. O MAI se estabelece como um instrumento de autorrelato, que avalia a consciência metacognitiva nos sujeitos. A validação nacional e tradução do MAI foi elaborada em uma pesquisa com estudantes do curso de Administração em um estado ao norte do país. Lima Filho e Bruni (2015, p. 1280) responsáveis pela validação - instituem que 14 de 52 outputs da escala original se aplicam ao contexto brasileiro.

Frente a esses dois testes e considerando o apresentado por Corso et al. (2013), considera-se que uma das mais marcantes disparidades entre a metacognição e as FE pode ser exemplificada nos métodos de mensuração de ambos os constructos. Os testes neuropsicológicos referentes às FE são tidos como objetivos, dessa forma utilizam medidas diretas de mensuração. Já os instrumentos metacognitivos, compostos sobretudo - por questionários vinculados a percepção dos próprios sujeitos sobre o modo que vivenciam seus processos, utilizam medidas indiretas de mensuração. Contudo, os testes representam possibilidades de uma autoconsciência, ou seja, de responder a partir de como o sujeito entende que sua estrutura cognitiva funciona e como ele percebe que opera com elas diante das diferentes ações do mundo cotidiano. Disso temos um aspecto a ser discutido pela comunidade acadêmica e que pode ser uma enseada na busca por aproximar metacognição e FE.

\section{CONSIDERAÇÕES FINAIS}

Inicialmente, os apontamentos gerados circundam, sobretudo, à lacuna presente quanto ao investimento em pesquisas voltadas a mensuração da metacognição em contextos sociais diversos. Sabe-se que sua aplicação no contexto educacional se estabelece de modo fortuito, na medida em que proporcionar aos alunos métodos de ensino que os façam protagonizar suas tarefas se apresenta como um efetivo catalisador na assimilação do conhecimento e seu posterior compartilhamento.

Não obstante, nessa perspectiva, deve-se assinalar que quanto maior o arcabouço metacognitivo do sujeito, maior sua propensão à aquisição dos conhecimentos. Dessa forma, a elucidação dos modos como os demais contextos vivenciais de um indivíduo opera, atrelados a metacognição, se desenrolará também como uma engrenagem Recebido em: $07 / 12 / 2020$ 
primordial no desenvolvimento de meios efetivos de se viver. Rosa $(2014$, p. 17) reitera que "o aspecto central está na potencialidade de cada sujeito e em sua capacidade de conhecer a si próprio, controlar e regular suas emoções". Por conseguinte, a elaboração de escalas neuropsicológicas - aptas a mensurar mecanismos metacognitivos de populações - se apresenta como um incisivo aliado na jornada rumo ao entendimento humano.

A educação exerce imenso protagonismo nas vivências dos sujeitos, ela é responsável pelo primeiro local de mediação entre o sujeito e a sociedade - através da escola. Maia Filho, Chaves e Freitas (2018) apresentam a produção de sujeitos autônomos como o cenário basal da educação. Não obstante, Souza, Petroni e Bremberger (2007) apontam as conflitivas vivenciadas pelos sujeitos ao se depararem com os níveis de adoecimentos tanto dos alunos, quanto dos professores. Infere-se que há certos processos, atravessados por diversos tecidos sociais, que refletem nas dificuldades para a aprendizagem - assim como para o ensino. Dessa forma, torna-se pertinente conhecer o modo como os alunos aprendem, uma vez que é a partir desse conhecimento que os professores podem propor alternativas didáticas que qualifiquem essa aprendizagem. Tomada de consciência.

No espectro apresentado, torna-se visível o ímpeto de maiores explanações a respeito da temática metacognição e $\mathrm{FE}$, enquanto estruturadores educacionais. Acredita-se que os sujeitos necessitam entender como aprendem e que isso se revela fundamental, sobretudo, na educação. Sem o discernimento de seus processos mentais, a transformação e seu aprimoramento transfiguram-se em fantasmas responsáveis pela estagnação do saber e consequentemente na mecanização dos processos relacionais. À vista disso, o entendimento dos constructos metacognitivos e executivos do aparato mental dos sujeitos refletem na educação enquanto formador de agentes críticos. $\mathrm{O}$ conhecimento apenas se torna acessível no momento em que os sujeitos se mostram conscientes de si mesmos - tal premissa representa a essência dos processos realizados pela metacognição, bem como pelas FE. A sensibilidade e a tomada de consciência do professor, como ressaltado por Schwingel e Araújo (2020) precisam ser considerados nos cursos de formação de professores. Com isso abre-se uma nova perspectiva de discussão, na qual questões como a metacognição e neurociência precisam começar a fazer parte dos currículos desses cursos.

Recebido em: $07 / 12 / 2020$

Aceite em: 25/08/2021 
Agradecemos ao CNPq - Código de Financiamento 001 - pelo apoio para o desenvolvimento desse estudo.

\section{REFERÊNCIAS}

ANDRETTA, Ilana; DA SILVA, Jaqueline Garcia; SUSIN, Nathália; FREIRE, Suzana Dias. Metacognição e Aprendizagem: como se relacionam?. Psico, v. 41, n. 1, p. 7-13, 2010.

BADDELEY, Alan. The episodic buffer: a new component of working memory?. Trends in cognitive sciences, v. 4, n. 11, p. 417-423, 2000.

BROWN, Ann L. Knowing when, where, and how to remember: a problem of metacognition. In: GLASER, Robert (Ed.). Advances in instructional psychology. Hillsdale, New Jersey: Lawrence Erlbaum Associates, 1978. v. 1. p. 77-165.

BROWN, Ann L. Metacognition, executive control, self-regulation, and other more mysterious mechanisms. In: WEINERT, Franz E.; KLUWE, Rainer H. (Eds.).

Metacognition, motivation and understanding. Hillsdale, New Jersey: Lawrence Erlbaum Associates, 1987. p. 65-116.

CORSO, Helena Vellinho; SPERB, Tânia Mara; JOU, Graciela Inchausti de; SALLES, Jerusa Fumagalli. Metacognição e funções executivas: relações entre os conceitos e implicações para a aprendizagem. Psicologia: teoria e pesquisa, v. 29, n. 1, p. 21-29, 2013.

COSENZA, Ramon Moreira; GUERRA, Leonor Bezerra. Neurociência e educação: como o cérebro aprende. Porto Alegre: Artemed, 2011.

DIAMOND, Adele. Understanding Executive Functions. Perspectives on language and literacy, v. 40, n. 2, p. 7-11, 2014.

FARIA, Camila de Assis; ALVES, Heloisa Veiga Dias; CHARCHAT-FICHMAN, Helenice. The most frequently used tests for assessing executive functions in aging. Dementia \& Neuropsychologia, v. 9, n. 2, p. 149-155, 2015.

FLAVELL, John H. Metacognition and cognitive monitoring: a new area of cognitive developmental inquiry. American Psychologist, v. 34, n. 10, p. 906-911, 1979.

FLAVELL, John H. Metacognitive aspects of problem solving. In: RESNICK, Lauren B. (Ed.). The nature of intelligence. Hillsdale, New Jersey: Lawrence Erlbaum Associates, 1976. p. 231-236.

Recebido em: $07 / 12 / 2020$

Aceite em: 25/08/2021 
GEORGHIADES, Petros. From the general to the situated: Three decades of metacognition. International Journal of Science Education, v. 26, n. 3, p. 365-383, 2004.

LIMA FILHO, Raimundo Nonato; BRUNI, Adriano Leal. Metacognitive Awareness Inventory: Tradução e Validação a partir de uma Análise Fatorial Confirmatória. Psicologia: ciência e profissão, v. 35, n. 4, p. 1275-1293, 2015.

MAIA FILHO, Osterne Nonato; CHAVES, Hamilton Viana; DE SOUSA SEIXAS, Pablo. Por uma educação para a autonomia de sujeitos situados no mundo. Psicologia da Educação, n. 46, 2018.

MARTÍ, Eduardo. Metacognición: entre la fascinación y el desencanto. Infancia y Aprendizaje, n. 72, p. 9-32, 1995.

MEDINA, Giovanna Beatriz Kalva. Intervenções em funções executivas, estratégias metacognitivas e consciência fonêmica em estudantes com dislexia do desenvolvimento. 2018. Tese (Doutorado em Educação) - Universidade Federal do Paraná, Curitiba, 2018.

PASCUALON-ARAUJO, Jussara Fátima; SCHELINI, Patrícia Waltz. Evidências de validade de uma escala destinada à avaliação da metacognição infantil. Psicologia: Teoria e Pesquisa, v. 31, n. 2, p. 163-171, 2015.

PERROTIN, Audrey; TOURNELLE, Lydia; ISINGRINI, Michel. Executive functioning and memory as potential mediators of the episodic feeling-of-knowing accuracy. Brain and Cognition, v. 67, n. 1, p. 76-87, 2008.

ROSA, Cleci T. Werner da. A metacognição e as atividades experimentais no ensino de Física. 2011. Tese (Doutorado em Educação Científica e Tecnológica) Universidade Federal de Santa Catarina, Florianópolis, Brasil, 2011.

ROSA, Cleci T. Werner da; SCHMITZ, Kymberly de Oliveira. A metacognição nas pesquisas em educação: uma revisão a partir das teses e dissertações brasileiras. Actio: docência em Ciências, prelo. 2020.

ROSA, Cleci T. Werner da. Metacognição no Ensino de Física: da concepção à aplicação. Passo Fundo: UPF Editora, 2014.

SABOYA, Eloisa; SARAIVA, Dagoberto; PALMINI, André; LIMA, Pedro; COUTINHO, Gabriel. Disfunção executiva como uma medida de funcionalidade em adultos com TDAH. Jornal Brasileiro de Psiquiatria, v. 56, p. 30-33, 2007.

SANTANA, Alanny Nunes de; MELO, Monilly Ramos Araujo; MINERVINO, Carla Alexandra da Silva Moita. Instrumentos de Evaluación de Funciones Ejecutivas: Revisión Sistemática de los últimos Cinco años. Avaliação Psicológica, v. 18, n. 1, p. 96-107, 2019. 
SCHRAW, Gregory; DENNINSON, Rayne Sperling. Assessing Metacognitive Awareness. Contemporary Educational Psychology, Nebraska, p. 460-475. 1994.

SCHWINGEL, Tatiane C. P. G.; ARAÚJO, Maria Cristina P. Compreensões de educação em saúde na formação inicial e continuada de professores. Revista Insignare Scientia - RIS, v. 3, n. 2, p. 368-385, 25 ago. 2020.

SOUZA, Vera Lúcia Trevisan de; PETRONI, Ana Paula; BREMBERGER, Maria Eufrásia de Faria. Psicologia, educação e a sociedade contemporânea: reflexões sob a perspectiva da Psicologia sócio-histórica. Psicólogo informação, v. 11, n. 11, p. 99112, 2007.

UEHARA, Emmy; LANDEIRA-FERNANDEZ, Jesus. Um panorama sobre o desenvolvimento da memória de trabalho e seus prejuízos no aprendizado escolar. Ciências \& Cognição, v. 15, n. 2, 2010.

VALE, Ricardo F. Aprendendo com leituras e textos: uma estratégia pedagógica para o ensino de Ciências da Natureza. Revista Insignare Scientia - RIS, v. 3, n. 2, p. 509520, 25 ago. 2020.

VALENZUELA, Ángel. ¿Qué hay de nuevo en la metacognición? Revisión del concepto, sus componentes y términos afines. Educação e Pesquisa, v. 45, p. 1-20, 2019.

WEINERT, Franz E. Metacognition and motivation as determinants of effective learning and understanding. In: WEINERT, Franz E.; KLUWE, Rainer (Orgs.). Metacognition, motivation, and understanding. Hillsdale, New Jersey: Laurence Erlbaum Associates, 1987. p. 1-16. 